\title{
A Numerical Study on the Relationships of Listeria and Erysipelothrix
}

\author{
By M. R. STUART* AND PHYLlis E. PEASE \\ Department of Bacteriology, University of Birmingham, Birmingham, BI $52 T J$
}

(Received 6 December I971; revised 2 August 1972)

SUMMARY

The physiological and general characters of 123 strains of Listeria were examined, and 33 of these were compared, in a computerized numerical analysis, with Erysipelothrix, Streptococcus, Corynebacterium, Microbacterium, Arthrobacter, Jensenia, Brevibacterium, Cellulomonas and Kurthia. It was concluded that Listeria and Erysipelothrix are distinct monospecific genera, not closely related.

On physiological grounds, Listeria bore the nearest resemblance to faecal streptococci, and Erysipelothrix to other streptococci.

\section{INTRODUCTION}

The relationships of the two groups of bacteria usually granted the rank of monospecific genera, Listeria monocytogenes and Erysipelothrix rhusiopathiae (formerly E. insidiosa), have been much disputed, and a detailed recapitulation of the stages of the argument is supererogatory. Standard, but divergent, views may be summarized in contrasting the opinions of Wilson \& Miles (I955) and of Bisset (1963), that they should be regarded as species in the same genus, with those of Breed, Murray \& Smith (Bergey's Manual, 1957), that both constitute genera in the family Corynebacteriaceae. The latter opinion was supported by numerical taxonomic studies produced by Davis \& Newton (I969), and Davis, Fomin, Wilson \& Newton (I969). The purpose of the present study is to provide the same type of evidence, using a larger number of strains.

\section{METHODS}

Strains studied. The strains used are listed in Table I. The 33 listerias were selected from I 23 strains for inclusion with the roo that could be accepted by the computer. They were considered to be representative, and included all recognized serotypes.

Media. TY medium (Davis \& Newton, 1969). TA medium (g/l): tryptose, I0; Lab Lemco beef extract, 3 ; blood agar base no. 2, 40. TYGP medium (g/l): tryptone, I0; yeast extract, 5 ; $\mathrm{NaCl}, 5 ; \mathrm{K}_{2} \mathrm{HPO}_{4}, 5 ;$ glucose, 2 . All were adjusted to $\mathrm{pH} 7 \cdot 2$ and sterilized by autoclaving at I $5 \mathrm{lb} / \mathrm{in}^{2}$ for $15 \mathrm{~min}$.

\section{Biochemical tests}

Methyl-red test. Medium (g/l): peptone, 5 ; glucose, $5 ; \mathrm{K}_{2} \mathrm{HPO}_{4}, 5$, adjusted to $\mathrm{pH} 7 \cdot 5$ and sterilized by autoclaving at $\mathrm{Io} \mathrm{lb} / \mathrm{in}^{2}$ for $\mathrm{I} 0 \mathrm{~min}$ after distribution into $\mathrm{IO} \mathrm{ml}$ amounts. Inoculation was from $24 \mathrm{~h}$ cultures on TA agar plates and incubation was for I4 days. A

* Present address: Botany Department, University of Rhodesia, Private Bag 162 H, Salisbury, Rhodesia. 
Table 1. Organisms employed in the computer analyses

Name

Arthrobacter sp.

A. globiformis

A. globiformis

A. simplex

A. tumescens

Brevibacterium linens

B. helvolum

Listeria monocytogenes (untyped)

L. denitrificans

L. grayi

Corynebacterium bovis

C. equi

C. haemolyticum

C. murium

C. ovis

C. renale

C. ulcerans

C. pyogenes

Corynebacterium $\mathrm{sp} . \mathrm{H}$

Corynebacterium $\mathrm{sp} . \mathrm{M}$

Corynebacterium sp. o

C. xerosis

Cellulomonas biazotea

C. flavigena

Corynebacterium tritici

C. michiganense

C. poinsettiae

C. poinsettiae

C. poinsettiae

C. betae

C. fascians

C. helvolum

Erysipelothrix rhusiopathiae

E. rhusiopathiae

E. rhusiopathiae

E. rhusiopathiae

E. rhusiopathiae

E. rhusiopathiae

E. rhusiopathiae

Jensen canicruria

Kurthia zopfii

Listeria monocytogenes (untyped)

L. monocytogenes (untyped)

Listeria sp. (Donna Craig) (untyped)

L. monocytogenes (serotype $3 \mathrm{a}$ )

$L$. monocytogenes (serotype $4 \mathrm{~d}$ )

L. monocytogenes (serotype 6)

L. monocytogenes (serotype 7)

L. monocytogenes (serotype 3c)

L. monocytogenes (serotype 5)

L. monocytogenes (serotype I a)

L. monocytogenes (serotype I a)

L. monocytogenes (serotype I a)

L. monocytogenes (serotype 2 a)

$L$. monocytogenes (serotype 2 a)

L. monocytogenes (serotype $3 \mathrm{~b}$ )

L. monocytogenes (serotype $4 \mathrm{~b}$ )

L. monocytogenes (serotype $4 \mathrm{e}$ )

L. monocytogenes (serotype 4 b)

L. monocytogenes (serotype $4 \mathrm{c}$ )
Source*

Strain no.

NIRD

NCIB

NCIB

Departmental

Departmental

1234

8907

8717

AS

AT

9909

NCIB $\quad 10352$

Dr B. Gittins

BGI

Dr D. Jones, MRC Unit, Leicester University

Dr D. Jones

NCTC

NCTC

NCTC

NCTC

NCTC

NCTC

NCTC

NCTC

NCTC

NCTC

NCTC

55134

C214

3224

I 62 I

8452

949

3450

$744^{8}$

7910

5224

6701

7146

7420

CXI

Departmental

NCIB

NCIB

8077

8073

255

NCPPB

NCPPB

I 468

177

854

855

363

$\mathrm{I} 488$

I 192

807

4304

2422

I 224

I 694

8163

10383

JI

404

KBR I

KBR2

KBR3

I035

I5O I

I 873

1775

1916

Ivanof

I 106

I I I I

I 24

2108

2107

3201

42 I 4

14

9258-65

4883 
Table I (cont.)

Name

L. monocytogenes (serotype $4 \mathrm{~b}$ )

L. monocytogenes (serotype $3 \mathrm{a}$ )

L. monocytogenes (serotype 4a)

L. monocytogenes (serotype I a)

L. monocytogenes (serotype 2)

L. monocytogenes (serotype $4 \mathrm{~b}$ )

L. monocytogenes (serotype I)

L. monocytogenes (serotype $4 \mathrm{~b}$ )

$L$. monocytogenes (serotype $4 \mathrm{~b}$ )

L. monocytogenes (serotype $4 \mathrm{~b}$ )

L. monocytogenes (serotype $4 \mathrm{~b}$ )

Microbacterium flavum

M. flavum

M. flavum

M. lacticum

M. lacticum

M. lacticum

M. lacticum

M. lacticum

M. lacticum

M. lacticum

M. lacticum

$M$. liquefaciens

$M$. liquefaciens

$M$. liquefaciens

$M$. thermosphactum

Streptococcus faecium

$S$. hominis

S. bovis

S. durans

S. faecalis

S. faecalis

S. agalactiae

Streptococcus в

Streptococcus $\mathrm{F}$

Streptococcus $\mathrm{MG}$
Source*

$\begin{array}{ll}\text { NCTC } & 4885 \\ \text { NCTC } & 5105 \\ \text { NCTC } & 5214 \\ \text { NCTC } & 7973 \\ \text { NCTC } & 9862 \\ \text { NCTC } & 9863 \\ \text { Professor H. P. R. Seeliger } & 881 \\ \text { Professor H. P. R. Seeliger } & 1920 \\ \text { Professor H. P. R. Seeliger } & 1962 \\ \text { Professor H. P. R. Seeliger } & 2015 \\ \text { Professor H. P. R. Seeliger } & 2027 \\ \text { NIRD } & 1320 \\ \text { Dr K. Robinson } & 3 \\ \text { Dr K. Robinson } & 19 \\ \text { NIRD } & 960 \\ \text { NIRD } & 747 \\ \text { NIRD } & 748 \\ \text { Dr K. Robinson } & 6 \\ \text { Dr K. Robinson } & 8 \\ \text { Dr K. Robinson } & 10 \\ \text { Dr K. Robinson } & 12 \\ \text { Dr K. Robinson } & 23 \\ \text { Dr K. Robinson } & 15 \\ \text { Dr K. Robinson } & 18 \\ \text { Dr K. Robinson } & 20 \\ \text { NIRD } & 1676 \\ \text { NCTC } & 7379 \\ \text { NCTC } & 7366 \\ \text { NCTC } & 8177 \\ \text { NCTC } & 8307 \\ \text { NCTC } & 8212 \\ \text { NCTC } & 4725 \\ \text { NCTC } & 818 \mathrm{I} \\ \text { NCTC } & 9412 \\ \text { NCTC } & 5389 \\ \text { NCTC } & 8037\end{array}$

* NIRD = National Institute for Research in Dairying; NCIB = National Collection of Industrial Bacteria, Aberdeen; NCTC = National Collection of Type Cultures, London; NCPPB = National Collection of Plant Pathogenic Bacteria, Harpenden, Hertfordshire.

small sample was transferred to an equal volume of methyl red (alcoholic solution) in a haemagglutination tray. A red coloration was scored as positive and yellow as negative.

Voges-Proskauer reaction. After a sample had been removed for the methyl-red test, $3 \mathrm{ml}$ of $5 \%(\mathrm{w} / \mathrm{v}) \alpha$-naphthol solution in absolute alcohol and I $\mathrm{ml}$ of $40 \%$ sodium hydroxide solution were added to each bottle. These were well shaken, the caps were removed, and they were allowed to stand open on the bench for $2 \mathrm{~h}$. A red coloration was scored as a positive result.

Phosphatase production. Phenolphthalein diphosphate Na salt was made as a I \% (w/v) aqueous solution and filter sterilized. The sterile substrate solution was incorporated at a concentration of $\mathrm{I} \mathrm{ml} / \mathrm{IOO} \mathrm{ml}$ of sterile melted TY agar, and poured into plates. Inoculation was from $24 \mathrm{~h}$ TY agar, and incubation was for 6 days at $30^{\circ} \mathrm{C}, 4$ days at $37^{\circ} \mathrm{C}$ and Io days at room temperature. Results were scored as positive if a pink colour became obvious under and/or around the colonies after flooding the plates with $15 \%(\mathrm{w} / \mathrm{v})$ aqueous sodium carbonate solution (Davis et al. 1969). 
Catalase production. Organisms were grown on TY agar base for $24 \mathrm{~h}$, or until growth was evident. A small amount of growth was transferred to a drop of Io volume hydrogen peroxide on a clean glass slide using the flame-rounded end of a Pasteur pipette, and the system was examined by means of a binocular plate microscope. The production of bubbles of oxygen around the cells within ro s was scored as positive catalase production.

Nitrate and nitrite reduction. Medium (a) (g/1): tryptone, Io; yeast extract, $5 ; \mathrm{NaCl}, 5$; glucose, $2 ; \mathrm{K}_{2} \mathrm{HPO}_{4}, 5 ; \mathrm{KNO}_{3}, 0 \cdot \mathrm{I}$. Medium $(b)(\mathrm{g} / \mathrm{l})$ : tryptone, Io; yeast extract, $5 ; \mathrm{NaCl}$, 5; glucose, $2 ; \mathrm{K}_{2} \mathrm{HPO}_{4}, 5 ; \mathrm{KNO}_{2}$, O.I. These media were autoclaved at $\mathrm{I}_{5} \mathrm{lb} / \mathrm{in}^{2}$ for $\mathrm{I}_{5} \mathrm{~min}$, inoculated from $24 \mathrm{~h}$ TYGP broth cultures and incubated for 6 days. The cultures were then tested by the addition of $0.1 \mathrm{ml}$ of each of the reagents A (sulphanilic acid, $0.5 \mathrm{~g}$, acetic acid, $30 \%(\mathrm{w} / \mathrm{v}), \mathrm{I} 50 \mathrm{ml}$ ) and $\mathrm{B}$ (I-naphthylamine, I g; distilled water $22 \mathrm{ml}$; $\left.\mathrm{CH}_{3} \mathrm{COOH} 30 \%(\mathrm{v} / \mathrm{v}), 178 \mathrm{ml}\right)$. Nitrate: the production of a red coloration was scored as positive reduction of nitrate to nitrate. To tubes not showing a red colour, powdered zinc was added to a weight approximately $5 \mathrm{mg} / \mathrm{ml}$ of culture, and after shaking allowed to stand. A red coloration now formed was scored as negative nitrate reduction. In the absence of colour, it was deduced that the nitrate had been reduced to nitrite, which was then further reduced. Such results were confirmed in the nitrite test. Nitrite: after addition of reagents A and $\mathrm{B}$ a red colour, indicating presence of nitrite, was scored as negative; absence of colour was scored as positive reduction.

Hydrogen sulphide production. Medium (a) TY broth; medium (b) TY broth $+0 \cdot \mathrm{I} \%(\mathrm{w} / \mathrm{v})$ $\mathrm{Na}_{2} \mathrm{~S}_{2} \mathrm{O}_{4}$; medium (c) TY broth $+0.05 \%$ (w/v) L-cysteine $\mathrm{HCl}$. The media were dispensed in bijoux bottles autoclaved at $15 \mathrm{lb} / \mathrm{in}^{2}$ for $15 \mathrm{~min}$, inoculated from $24 \mathrm{~h}$ TY broth cultures and incubated for Io days. Small strips of sterile filter paper which had been soaked in saturated aqueous lead acetate solution were transferred aseptically to each tube, and held in place above the medium by means of the screw cap. The cultures were examined daily for blackening of the acetate paper; such blackening was scored as a positive result, unless the degree of darkening in the media containing L-cysteine or thiosulphate was not greater than that produced in the TY broth without additions. In this case only the TY broth result was scored as a positive result.

Indole production. TY broth was inoculated from $24 \mathrm{~h}$ TY broth cultures, and incubated for 6 days. A $\mathrm{I} \mathrm{ml}$ portion of ether was added to each tube, and after shaking $0.5 \mathrm{ml}$ Ehrlich's reagent was run down the side of the tube. A pink or red colour in the solvent layer was scored as a positive result.

Production of acetic acid from ethanol. Light calcium carbonate $(1 \% \mathrm{w} / \mathrm{v})$ was added to TY agar base, and the medium autoclaved at $15 \mathrm{lb} / \mathrm{in}^{2}$ for $\mathrm{I} 5 \mathrm{~min}$. The sterile medium was cooled to $45^{\circ} \mathrm{C}$ and $2 \%$ (v/v) final concentrated ethanol (absolute alcohol or 74 O.P.) in sterile distilled water was added aseptically. Plates were inoculated from $24 \mathrm{~h}$ TYGP broth cultures, incubated for 14 days, and examined daily for zones of clearing around the bacterial growth. In the final reading, growth was scraped aside to detect weak reactions under the colonies. Any clearing was scored as positive.

Polysaccharide production. Sterile sucrose solution was added aseptically to melted TY agar base to give a final concentration of $3 \%(\mathrm{w} / \mathrm{v})$. Plates were inoculated from $24 \mathrm{~h}$ TYGP broth cultures. After incubation for 6 days any evidence of mucoid colonies was recorded as positive polysaccharide production.

Aesculin hydrolysis. Medium (g/l): proteose peptone, I0; yeast extract, 5; sodium acetate, Io; aesculin, 5 ; Tween 80 , I $\mathrm{ml}$. The broth was autoclaved for $\mathrm{IO} \mathrm{min}$ at Io $\mathrm{lb} / \mathrm{in}^{2}$, inoculated from $24 \mathrm{~h}$ TY broth cultures and incubated for 6 days; any loss of fluorescence and blackening was scored as positive hydrolysis. 
Casein hydrolysis. Medium (g/l): tryptone, ro; yeast extract, $5 ; \mathrm{NaCl}, 5$; casein, Io; Oxoid agar no. 3, 15. Autoclaving was at $15 \mathrm{lb} / \mathrm{in}^{2}$ for $15 \mathrm{~min}$, inoculation was from $24 \mathrm{~h}$ TY broth cultures and incubation was for 6 days. Positive results were scored when, after flooding with acid mercuric chloride solution, a clear zone remained around the colonies.

Hippurate hydrolysis. Medium (g/l): Na hippurate, I0; tryptone, Io; yeast extract, 5; $\mathrm{K}_{2} \mathrm{HPO}_{4}, 5 ; \mathrm{NaCl}, 5$. The broth was autoclaved at $\mathrm{I} 5 \mathrm{lb} / \mathrm{in}^{2}$ for $15 \mathrm{~min}$. Inoculation was from $24 \mathrm{~h}$ TYGP broth cultures, and incubation was for 6 days. Uninoculated control tubes were also incubated. To I $\mathrm{ml}$ volumes of the control media, varying amounts $(0.2$ to $0.5 \mathrm{ml}$ ) of acid ferric chloride solution $\left(\mathrm{FeCl}_{3}\right.$, I2 $\mathrm{g}$; conc. $\mathrm{HCl}, 2.5 \mathrm{ml} / 0 \cdot \mathrm{I}$ 1) were added and immediately shaken. The smallest volume to give a clear solution was added to $\mathrm{I} \mathrm{ml}$ samples of clear supernatant fluid from the broth cultures. A heavy precipitate was scored as a positive hydrolysis.

Hydrolysis of chitin and alginate. Chitin: for use in a solid medium it was necessary to obtain chitin in a finely dispersed condition. Granular chitin ( $10 \mathrm{~g}$ ) was placed in a 31 flask, and $\mathrm{r} 500 \mathrm{ml}$ of distilled water was held in readiness in another flask. A $100 \mathrm{ml}$ sample of $50 \%(\mathrm{v} / \mathrm{v})$ sulphuric acid was added to the granular chitin, and, as soon as this was seen to dissolve, the acid was rapidly diluted with the $1500 \mathrm{ml}$ of distilled water. The resulting precipitate was allowed to settle overnight and the supernatant then decanted off. The finely divided chitin sludge so formed was dialysed against running water for 2 days to free it from acid. The chitin was resuspended in distilled water to a density such that after diluting $\mathrm{I}: \mathrm{I}, 5 \mathrm{ml}$ of it dispensed in a Petri dish gave a distinct opalescence. A $50 \mathrm{ml}$ portion of resuspended chitin was added to $450 \mathrm{ml}$ melted TY agar base, the $\mathrm{pH}$ adjusted to $7 \cdot 2$, and then it was autoclaved for $15 \mathrm{~min}$ at $\mathrm{I} 5 \mathrm{lb} / \mathrm{in}^{2}$. Plates were inoculated from $24 \mathrm{~h}$ TYGP broth cultures and incubation was for 12 days. A zone of clearing under or around the bacterial colonies was scored as a positive result. Alginate: sodium alginate to a final concentration of $\mathrm{I} \%(\mathrm{w} / \mathrm{v})$ was added to $\mathrm{TY}$ agar, the $\mathrm{pH}$ adjusted to 7.0 with $\mathrm{HCl}$, and the medium then autoclaved at $15 \mathrm{lb} / \mathrm{in}^{2}$ for $15 \mathrm{~min}$. The sterile melted medium was poured into plates in a layered manner - $\mathrm{IO} \mathrm{ml}$ to $\mathrm{IO} \mathrm{ml}$ of solidified TY agar in the Petri dish. Inoculation was from $24 \mathrm{~h}$ TYGP broth cultures, and incubation was for I 2 days. At intervals the plates were examined for clarification of the agar around the colonies, and where this occurred digestion of the alginate resulted in a pitting of the agar. Such clearing was scored as a positive alginate hydrolysis.

Ammonia from arginine. Medium (g/l): tryptone, Io; yeast extract, $5 ;$ glucose, $2 ; \mathrm{NaCl}, 5$; $\mathrm{K}_{2} \mathrm{HPO}_{4}$, 5; L-arginine monohydrochloride, 3. The medium was adjusted to $\mathrm{pH} 7{ }^{\circ}$, and autoclaved at $\mathrm{I} 5 \mathrm{lb} / \mathrm{in}^{2}$ for $\mathrm{I} 5 \mathrm{~min}$. Inoculation was from $24 \mathrm{~h}$ TYGP broth cultures, and after 3 days of incubation $0.25 \mathrm{ml}$ Nessler's reagent was added to both the test media, and to a set of control media in which the arginine had been omitted. The formation of a brown colour was scored as positive.

Bile tolerance. Sodium deoxycholate was added to melted TY agar base to give final concentrations of $2 \%$ and $5 \%(\mathrm{w} / \mathrm{v})$. Plates were poured and inoculated from $24 \mathrm{~h}$ TYGP broth cultures, and after incubation for 6 days any growth was scored as a positive reaction.

Benzidine reaction. Benzidine dihydrochloride reagent was prepared according to the method of Deibel \& Evans (I960). Organisms were grown on TY agar for 3 days, then flooded with the reagent, followed by an equal volume of $5 \%$ hydrogen peroxide after $2 \mathrm{~min}$. Development of a blue coloration in the colonies was scored as a positive reaction.

Hydrogen peroxide production. Blood was added to TY agar base to give a final concentration of $5 \%(\mathrm{v} / \mathrm{v})$. Benzidine solution (Benzidine, $0.25 \mathrm{~g} ; 25 \% \mathrm{HCl}, 0.35 \mathrm{ml} / 0.051$ ) was added to the melted blood agar to a final concentration of $0.01 \%(\mathrm{w} / \mathrm{v})$. Plates were poured, 
Table 2

Computer run A (physiological)

Methyl-red positive

Alginate hydrolysis

Chitin hydrolysis

Xanthine decomposition

Tyrosine decomposition

Phenylalanine decomposition

Malonate

Hippurate hydrolysis

Starch hydrolysis

Phosphatase

Ammonia from arginine

Voges-Proskauer positive

Gluconate

Gelatine hydrolysis

Casein hydrolysis

Tolerance of $2 \%$ bile

Arylsulphatase

Ethanol to acetic acid

Dihydroxyacetone from glycerol

Catalase produced

Calcium lactate to carbonate

Salicylate hydrolysis

Aesculin hydrolysis

Nitrate reduced

Nitrite reduced

Hydrogen sulphide from TY broth

Hydrogen sulphide from TY broth plus thiosuphate

Hydrogen sulphide from TY broth plus I-cysteine

Benzidine reaction

Benzidine blood reaction

Polysaccharide produced

Indole positive

Growth on pyronin

Enhancement of haemolysis on azide blood agar

Pigment produced on TY agar

Growth at pH 5.6

Growth at $\mathrm{pH} 6 \cdot 2$

Growth at $\mathrm{pH} 7.0$

Growth at $\mathrm{pH} 8.0$

Growth at $\mathrm{pH} 9.6$

Growth in $4 \% \mathrm{NaCl}$

Growth in $6 \% \mathrm{NaCl}$

Growth in $8 \% \mathrm{NaCl}$

Growth in $10 \% \mathrm{NaCl}$

Growth in $\mathrm{KCN}$ broth

Growth at $4^{\circ} \mathrm{C}$

Growth at $10^{\circ} \mathrm{C}$

Growth at $30^{\circ} \mathrm{C}$

Growth at $37^{\circ} \mathrm{C}$

Growth at $45^{\circ} \mathrm{C}$

Tolerance of $0.05 \%$ Teepol

Tolerance of $0.1 \%$ Teepol

Tolerance of $0.5 \%$ thallous acetate

Tolerance of $0.1 \%$ thallous acetate

Reduction of $0.1 \%$ potassium tellurite

Reduction of $0.1 \%$ potassium selenite

Tolerance of $0.005 \%$ sodium azide
Computer run B (variety of characteristics)

Rods present in 3 day TY agar

Cocci

Length less than $\mathrm{I} \cdot 5 \mu \mathrm{m}$

Length greater than $\mathrm{I} \cdot 5 \mu \mathrm{m}$

Singles

Pairs

Chains

Filaments

Curved

Club-shaped

Branched

Motile at 22 or $37^{\circ} \mathrm{C}$

Pigment green, yellow or pink

Gram-positive

Gram-variable

Snapping division or angular growth

Evidence of morphological cycle

Origin plant

Origin animal

Human pathogen (isolated from human disease)

Non-pathogenic

Wide distribution

Indole positive

Catalase positive

Voges-Proskauer positive

Benzidine reaction

Benzidine blood reaction

Methyl-red positive

Sodium azide $0.005 \%$ tolerance

Sodium azide $0.05 \%$ tolerance

Sodium iodoacetate $0.0005 \%$ tolerance

Sodium iodoacetate $0.05 \%$ tolerance

Acid produced from:

Rhamnose

Glucose

Sucrose

Mannose

Salicin

Arabinose

Melezitose

Mannitol

Erythritol

Xylose

Lactose

Maltose

Fructose

Starch

p-Arbutin

Cellobiose

Dextrin

Resistance to:

Streptomycin

Bacitracin

Erythromycin

Tetracycline

Ampicillin

Resistance to:

Penicillin G

Cephaloridine

Chloramphenicol 
Table 2 (cont.)

Computer run A (physiological)

Tolerance of $0.05 \%$ sodium azide

Growth on $0.0002 \%$ Thionin

Growth on $0.01 \%$ Thionin

Reduction of $0.05 \%$ TTC

Tolerance of $0.0005 \%$ sodium iodoacetate

Tolerance of $0.005 \%$ sodium iodoacetate

Tolerance of $0.05 \%$ sodium iodoacetate

Growth on $0.01 \%$ Crystal violet

Growth on $0.1 \%$ Crystal violet

$\alpha$-Haemolysis

$\beta$-Haemolysis

Cloudiness on Tween 20

Cloudiness on Tween 80
Computer run B (variety of characteristics)

Resistance to

Chlortetracycline

Neomycin

Oleandomycin

Oxytetracycline

Novobiocin

Kanamycin

Detection of amino acids in cell wall:

Aspartic acid

Alanine

Glutamic acid

Lysine

Diaminopimelic acid

Serine

Glycine

inoculated from $24 \mathrm{~h}$ TY broth cultures and incubated for 3 days. Black colony formation was scored as negative peroxide production.

Utilization of carbohydrates. Bacterial suspensions: strains were grown on TY agar for $24 \mathrm{~h}$ at $37^{\circ} \mathrm{C}, 3$ days at $30^{\circ} \mathrm{C}$ or 7 days at room temperature, harvested in saline, centrifuged at $2000 \mathrm{~g}$ for $10 \mathrm{~min}$, washed once in saline and resuspended to a density approximately corresponding to that of Brown's opacity tube no. 3. Carbohydrates tested: the following carbohydrates were made up in distilled water at the concentration stated $(\%, w / v$, unless otherwise indicated), and sterilized by steaming for $20 \mathrm{~min}$ on 3 consecutive days: arabinose, 5 ; xylose, 25 ; rhamnose, 5 ; glucose, 25 ; fructose, 15 ; mannose, 5 ; galactose, 20 ; sucrose, 25; maltose, 25; lactose, 25; trehalose, 5; raffinose, Io; melezitose, 5; starch, 5; inulin, I0; dextrin, I0; glycerol, 25 (v/v); erythritol, 5 ; adonitol, 2.5 ; mannitol, 5 ; du lcitol, 5; sorbitol, 5 ; salicin, 5 ; aesculin, 2 ; inositol, 5 ; cellobiose, 5 ; melibiose, 5 ; $p$-arbutin, 2.5 . All carbohydrates were adjusted to give a final concentration of $\mathrm{I} \%$. The buffer indicator solution was made up of ethanolic bromcresol purple I \% solution $0.5 \mathrm{ml}+$ phosphate buffer $0.025 \mathrm{M}, \mathrm{pH} 6.8,20 \mathrm{ml}$. Tubes were inoculated with the following test mixture: carbohydrate solution, $0.1 \mathrm{ml}$; buffer-indicator solution, $0.2 \mathrm{ml}$; bacterial suspension, $0.2 \mathrm{ml}$, and incubated in a $37^{\circ} \mathrm{C}$ water bath and examined at 4,8 and $24 \mathrm{~h}$. A positive acid production was scored when the colour changed from purple to yellow.

Starch hydrolysis. Soluble starch $(5 \mathrm{~g})$ was ground in a mortar with $2.5 \mathrm{ml}$ distilled water to produce a smooth paste. This was added to $500 \mathrm{ml}$ blood agar base no. 2 (Oxoid), mixed, and autoclaved at Io $\mathrm{lb} / \mathrm{in}^{2}$ for Io min. Plates were inoculated from $24 \mathrm{~h} \mathrm{TY}$ agar cultures and were incubated for 6 days. Lugol's iodine was flooded over the plates, and positive reactions were scored when colourless zones were detected under or around the colonies.

Gelatin hydrolysis. Medium (g/l): tryptone, 10 ; yeast extract, $5 ; \mathrm{NaCl}, 5$; gelatin, 4 ; Oxoid agar no. 3 , I5. Sterilization was at $10 \mathrm{lb} / \mathrm{in}^{2}$ for $10 \mathrm{~min}$, and plates were inoculated from $24 \mathrm{~h}$ TYGP broth cultures. After incubation for $\mathrm{I} 2$ days, the plates were flooded with Io $\mathrm{ml}$ acid mercuric chloride solution. Clear zones around colonies indicating areas of gelatin hydrolysis were scored as positive.

Gluconate oxidation. Medium (g/l): tryptone, Io; yeast extract, $5 ; \mathrm{K}_{2} \mathrm{HPO}_{4}, 5 ; \mathrm{NaCl}, 5$; sodium gluconate, $37 \cdot 25$. The $\mathrm{pH}$ was adjusted to $7 \cdot 0$ and the medium was dispensed in $5 \mathrm{ml}$ volumes, autoclaved at $\mathrm{I} 5 \mathrm{lb} / \mathrm{in}^{2}$ for $\mathrm{I} 5 \mathrm{~min}$, inoculated from $24 \mathrm{~h}$ TYGP broth cultures, and incubated for 6 days. A I ml sample of Benedict's solution was then added to each 
tube and the tubes boiled for Io min. The formation of a green, brown or orange precipitate was scored as a positive result.

\section{Miscellaneous tests}

Ribonuclease and deoxyribonuclease activity were tested by the method of Jeffries, Holtman \& Guse (1957); haemolysis, and the effect upon it of sodium azide, by that of Packer (1943); arylsulphatase, by that of Luppi, Prati \& Baretta (1964); malonate decomposition and the production of dihydroxyacetone, according to Harrington (1964); decomposition of tyrosine and xanthine, according to Skerman (1967); phenylalanine deamination, according to Shaw \& Clarke (I955); oxidation of calcium lactate to carbonate, according to Shimwell, Carr \& Rhodes (1960); and coagulase production, according to Cowan (1938).

\section{Sensitivity and tolerance tests}

The various agents and concentrations used in these tests are listed in Table 2. Tolerance of $\mathrm{pH}$ was tested in tryptone broth (Oxoid), inoculated from $24 \mathrm{~h}$ TYGP broth cultures and incubated for 6 days. Antibiotics were tested on TY agar, by means of Mast sensitivity discs, and incubated at 37 and $30^{\circ} \mathrm{C}$ for 5 days. Temperature tolerance was measured on TY or TA medium, in the form of slopes, and incubated for up to 2 weeks. Potassium tellurite (Seeliger, 196I; Kramer \& Jones, 1969) and potassium selenite (Mohanty, I95I) were prepared as $2 \%(\mathrm{w} / \mathrm{v})$ solutions, sterilized by Seitz filtration and added to TY agar medium; sodium azide (Kramer \& Jones, 1969) and sodium iodoacetate were prepared in the same manner, but as $10 \%$ and I \% solutions respectively. Potassium cyanide (Kramer \& Jones, 1969) was prepared in TYGP medium, by adding a $0.5 \%(\mathrm{w} / \mathrm{v})$ solution in distilled water, to the autoclaved broth. Thallous acetate (Shape, 1952) was prepared as a $10 \%(\mathrm{w} / \mathrm{v})$ solution, autoclaved at $10 \mathrm{lb} / \mathrm{in}^{2}$ for $10 \mathrm{~min}$, and added to TY agar medium. Furacin was prepared according to the technique of McBride \& Girard (I960); 2,3,5-triphenyltetrazolium chloride (TTC) by that of Kramer \& Jones (I969). Dyes (Pacheco \& Santos, 1957; Roberts I968; and others) were incorporated in TY agar plates.

\section{Cell wall analysis}

These observations were made by the methods of Cummins \& Harris (1956, 1958) and Davis \& Baird-Parker (1959).

\section{Morphology}

Gram's stain, cell wall staining by the method of Hale (I953), electron and phase-contrast microscopy were employed to examine the morphology of the bacteria studied. Pigmentation and morphology of colonies was observed.

\section{General characters}

Such characters as origin (i.e. from plant or animal infection, or soil) pathogenicity or wideness of distribution are given according to the descriptions of those who isolated or identified and recorded the various strains.

\section{Computer programme}

A list of the characters computed for the bacteria in Table I is given in Table 2. The programme was essentially similar to that used by Seyfried (I968) in her study of lactobacilli, but modified for use in the Egtran II system employed on the Birmingham University KDF 9 computer. The steps in the programme included the following: calculation of a 


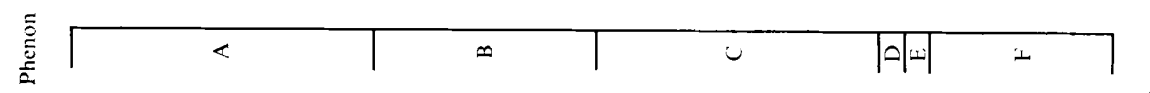

灵

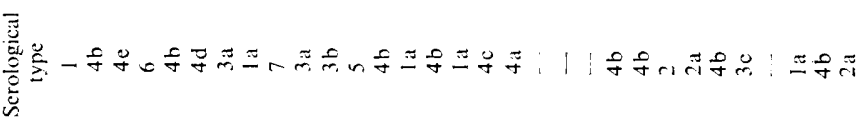

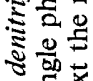

楌
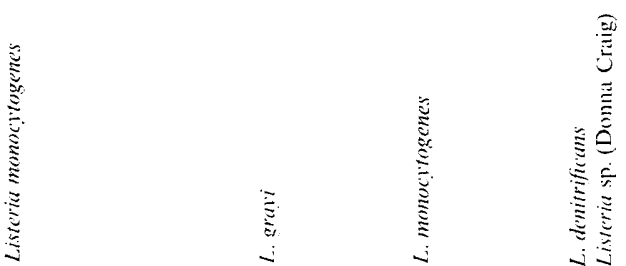

들

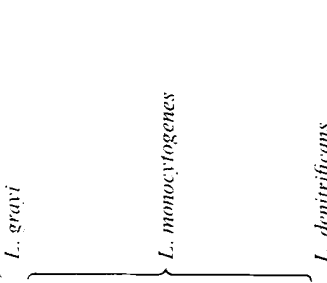

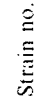
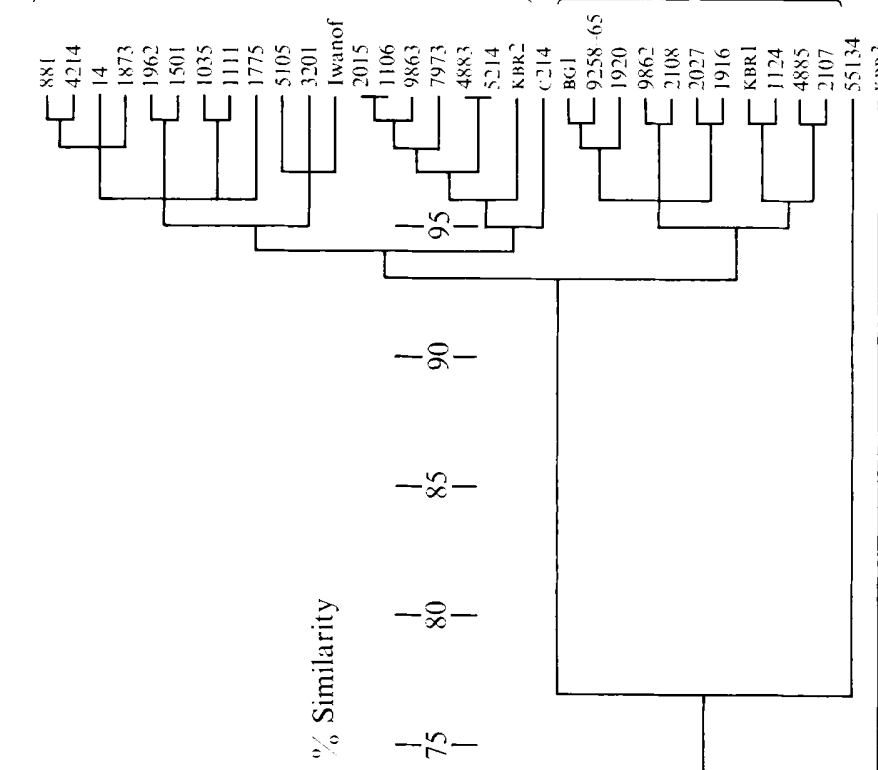

-Rー

$-8-$

$-8-$

$-n-$

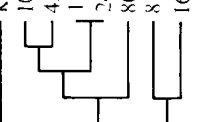

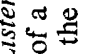

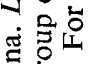

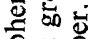

용

冚

$\div$ I

on

密

ธิธูป

오원

क.

近

远

宓

ส.8

E 蛋

웡

今

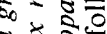

공ำ

근.

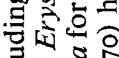

造爮

氙

氙过

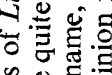

品

额的跑

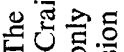

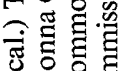

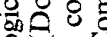

응

क क

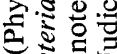

诘通五

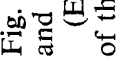


560

M. R. STUART AND P. E. PEASE

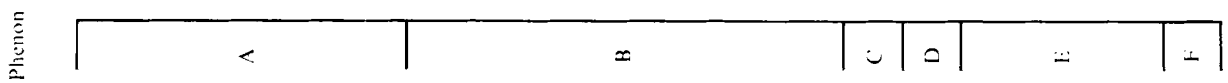

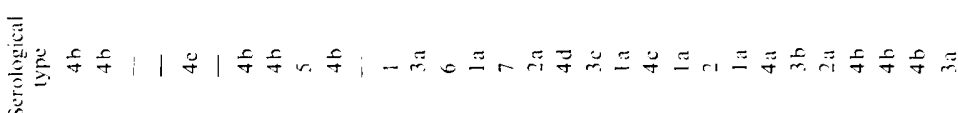

בั้

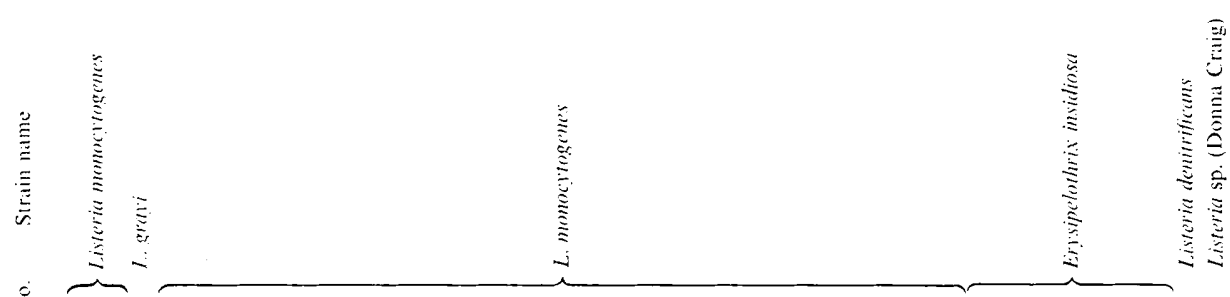

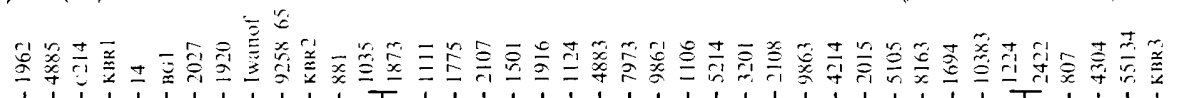

$\prod_{1}^{\infty}$
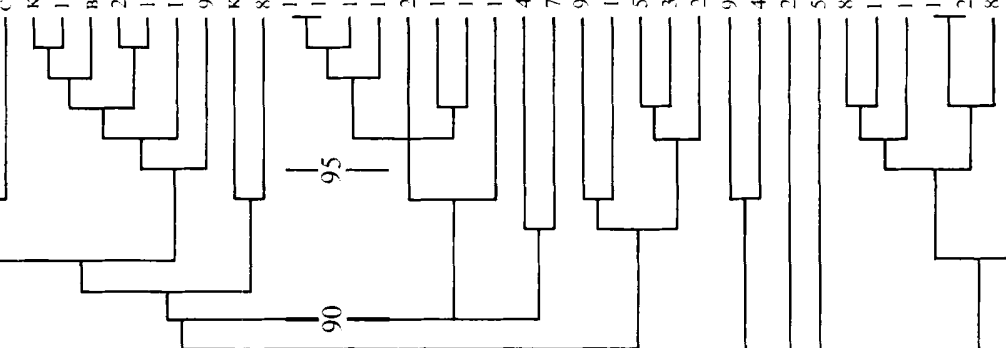

政
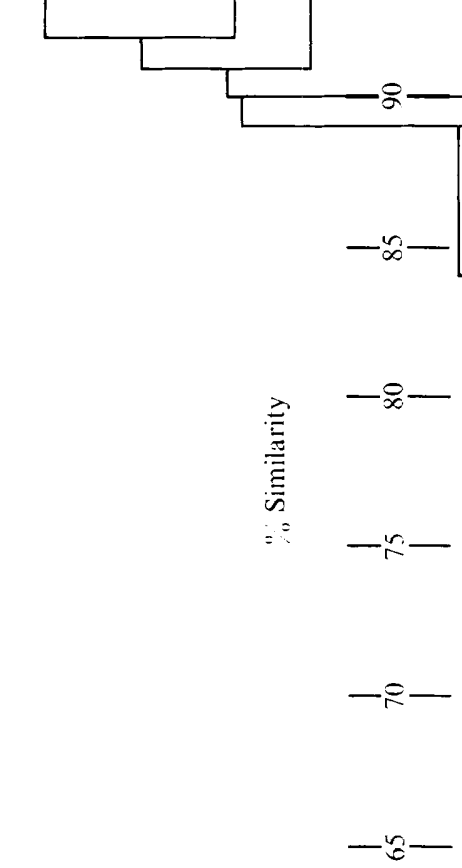

$-8-$

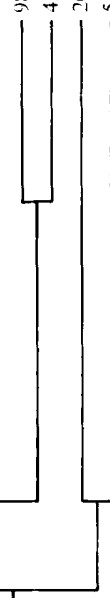

焉

5.

密空

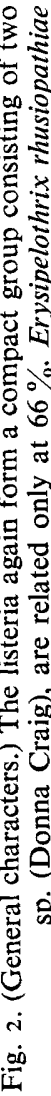




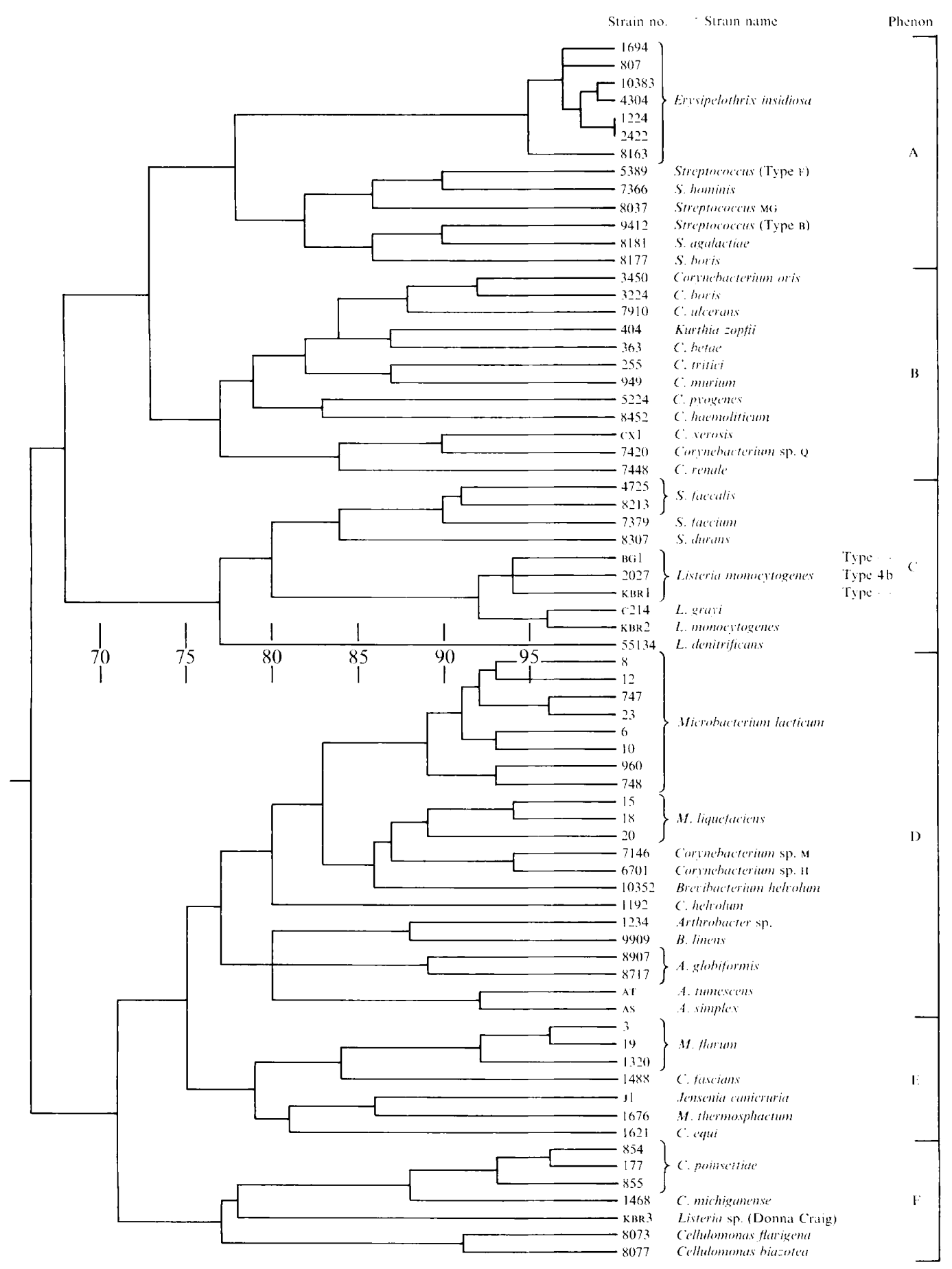

Fig. 3. (Physiological.) Erysipelothrix rhusiopathiae (syn. E. insidiosa) and the true Listeria strains (see Fig. I and 2) form compact groups; the former in a phenon with haemolytic streptococci, the latter with faecal streptococci. These two phena are most closely related to a third comprising the corynebacteria of animal origin. 


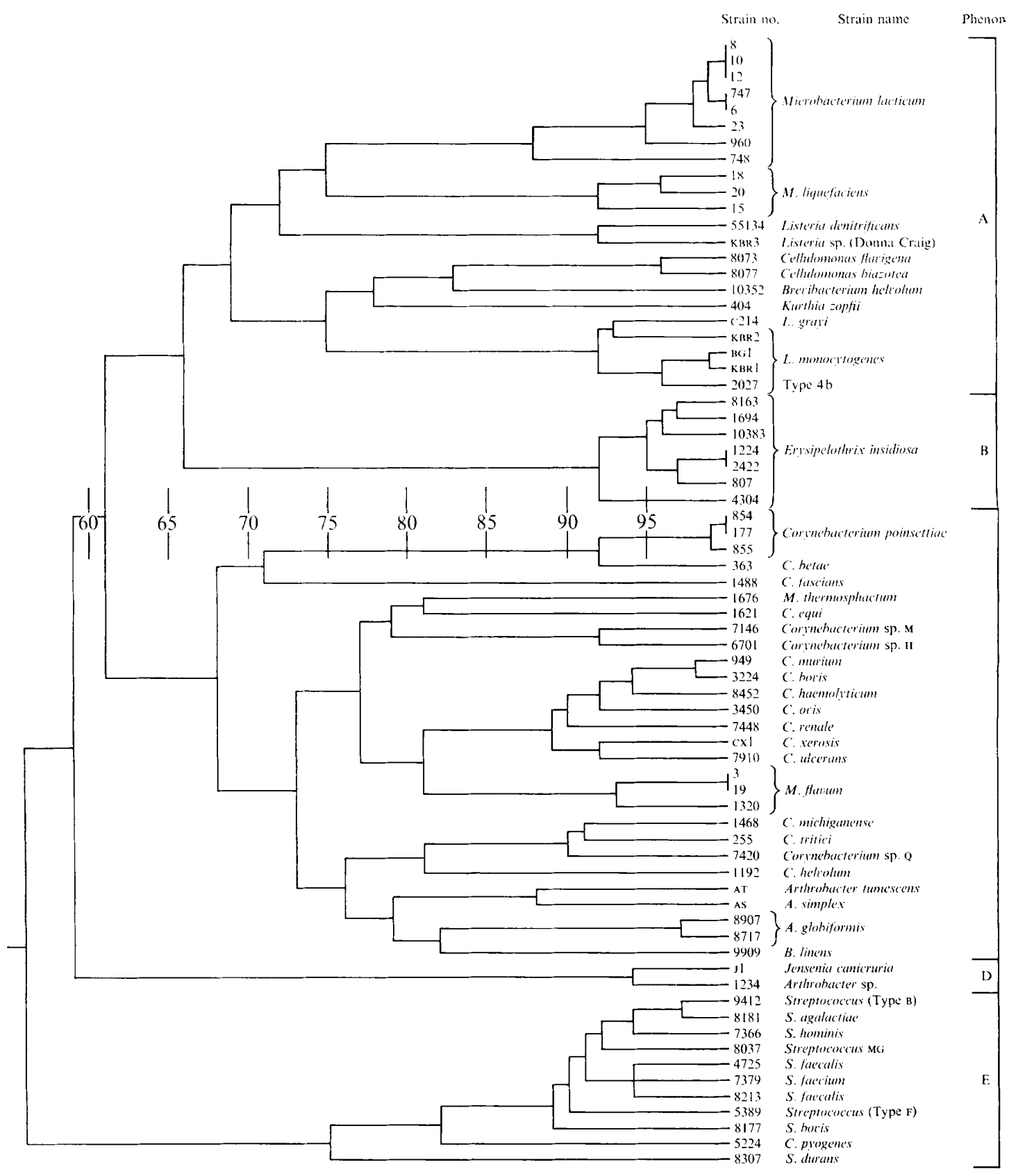

Fig. 4. (General characters.) By these criteria, Erysipelothrix rhusiopathiae (syn. E. insidiosa) forms a single phenon, whereas true listerias, while still a compact group, appear in a phenon with some corynebacteria, soil diphtheroids and microbacteria. 
matrix of similarity coefficients for all possible pairs of strains; grouping of strains with highest similarity into clusters; and calculation of new similarity coefficients between clusters, repeated until all strains were grouped in one cluster. These coefficients ( $S$ values) were determined by the method of Sokal \& Michener (1958), using the formula $S=N S /(N S+N D)$, where $N S$ was the number of similar features and $N D$ the number of differences.

The program analysed 100 specimens, with 70 characteristics. Because of the large number of characteristics available, these were analysed in two groups: run A, 70 physiological characters; and run B, 70 mixed characters (Table 2). This arrangement was chosen because it is considered that previous conclusions on the classification of Listeria have been affected by the types of criteria chosen for analysis. For example, Miller \& Silverman (I959) found Listeria monocytogenes to be related to lactobacilli on almost purely metabolic grounds, whereas others (Davis \& Newton, 1969, and others) concluded that both listerias and Erysipelothrix rhusiopathiae resembled the corynebacteria of animal provenance; these views being based on a more general list of characters.

\section{RESULTS AND DISCUSSION}

The results of these analyses are given in the form of dendrograms, of which Fig. I and 2 show the option I analysis (simple matching coefficient) for the listerias and Erysipelothrix rhusiopathiae strains only, using the physiological characters (run A) and the general characters (run B) respectively. They show clearly that these two genera are distinct, and that each forms a compact group of strains. Listeria grayi is indistinguishable from L. monocytogenes, whereas L. denitrificans and Listeria sp. (Donna Craig) are quite different. As far as $L$. denitrificans is concerned these observations are supported by the difference in its GC ratio from that of other listerias (Welshimer \& Meridith, I97I). The genus can reasonably be said to consist of a single species, since the various phena, into which it is divisible, on each analysis, have no correlation between the two runs, A and B. No correlation was observed between the composition of the strains in the phena with either serological type or source. Erysipelothrix rhusiopathiae may similarly be regarded as a monospecific genus, and in this case it constitutes a single phenon, alike in both runs.

Fig. 3 and 4 show option I analysis for all the bacteria studied, on runs A and B respectively. When physiological characters, only, are considered (run A), Erysipelothrix rhusiopathiae appears as a compact group, sharing one phenon with the streptococci, other than the faecal ones. The latter share a phenon with the five typical strains of Listeria (out of the seven strains, including Listeria denitrificans and Listeria sp. (Donna Craig), that were chosen as representative of the genus, to balance the seven strains of $E$. rhusiopathiae and comparable numbers from other bacterial genera shown on this graph. Both of these phena are related to one comprising a group of corynebacteria, mainly of animal origin; at $67 \%$ for the listeriae, and $73 \%$ for E. rhusiopathiae. However, their relationship to the remaining strains is only $2 \%$ lower, and on the full range of characters, in Fig. 4, no such relationships appear, above $6 \mathrm{r} \%$, and the streptococci are distinct. The strains of Listeria form a loose group with the microbacteria, and a closer one with a collection of rather ill-defined diphtheroid bacilli of diverse origins.

The one observation of genuine interest provided by these attempts to solve the problem of the relationships of the genera is the close affinity between the listerias and the faecal streptococci, shown in Fig. 3. There is direct serological evidence for such a relationship (Seeliger, 196I), and also indirect evidence, in that Pease (1967a) showed certain listeria like bacteria possessed L-forms that closely resembled Mycoplasma hominis, whereas the 
latter organism has strong serological cross-relationships with strains of Streptococcus aecalis (Pease, $1967 b$ ). However, the significance of the so-called Rantz antigen common to a wide range of Gram-positive bacteria (Neter, Anzai \& Gorzynski, 1960) is not clear and we are currently engaged in work on this problem.

The results of the tests on which the numerical analysis is based may be obtained on application to the authors.

We wish to acknowledge the assistance of Mr B. C. Kershaw, Computer Centre, University of Birmingham.

\section{REFERENCES}

Bisset, K. A. (1963). Bacteria, 3rd edn, p. 75. Edinburgh: Livingstone.

Bergey's Manual of Determinative Bacteriology (1957), 7th edn, p. 578. Edited by R. S. Breed, E. G. D. Murray and N. R. Smith. Baltimore: Williams \& Wilkins.

CowAN, S. T. (1938). The classification of staphylococci by precipitation and biological reactions. Journal of Pathology and Bacteriology 46, 31-45.

Cummins, C. S. \& Harris, H. (I956). The chemical composition of the cell wall in some Gram-positive bacteria and its possible value as a taxonomic character. Journal of General Microbiology 14, 583-60o.

Cummins, C. S. \& Harris, H. (1958). Studies on the cell-wall composition and taxonomy of Actinomycetales and related groups. Journal of General Microbiology 18, 173-189.

Davis, G. H. G. \& Baird-PARKer, A. C. (1959). The classification of certain filamentous bacteria with respect to their chemical composition. Journal of General Microbiology 2I, 6I 2-62 I.

Davis, G. H. G., Fomin, L., Wilson, E. \& Newton, K. G. (1969). Numerical taxonomy of Listeria, Streptococci and possible related bacteria. Journal of General Microbiology 57, 333-348.

DAVIS, G. H. G. \& NEWTON, K. G. (1969). Numerical taxonomy of some named coryneform bacteria. Journal of General Microbiology 56, 195-2I4.

Deibel, R. H. \& Evans, J. B. (1960). Modified benzidine test for the detection of cytochrome containing respiratory systems in micro-organisms. Journal of Bacteriology 79, 356-360.

HALE, C. M. F. (I953). The use of phosphomolybdic acid in the mordanting of bacterial cell walls. Laboratory Practice 2, II 5-116.

HARRINGton, B. (I964). The taxonomy of oral corynebacteria, p. 75. Ph.D. Thesis, University of Birmingham.

Jeffries, C. D., Holtman, D. F. \& Guse, D. J. (1957). Rapid method for detecting the activity of microorganisms on nucleic acids. Journal of Bacteriology 73, 590-591.

Kramer, P. A. \& Jones, D. (1969). Media selective for Listeria monocytogenes. Journal of Applied Bacteriology 32, $38 \mathrm{I}-394$.

Luppi, A., Prati, L. \& Baretta, G. (1964). Su alcune caratteristiche metabolico-culturali della Listeria monocytogenes. II. Attivita arylsolfatasica della Listeria monocytogenes. Bollettino dell'Istituto Sieroterapico Milanese 43, 209-2I 2 .

MCBride, M. E. \& GiRARD', K. F. ( I960). A selective method for the isolation of Listeria monocytogenes from mixed bacterial populations. Journal of Laboratory and Clinical Medicine 55, I 53-I57.

Miller, I. L. \& Silverman, S. J. (1959). Glucose metabolism of Listeria monocytogenes. Bacteriological Proceedings, I03.

Mohanty, U. (195I). Corynebacterium fascians (Tilford) Dowson: its morphology, physiology, nutrition and taxonomic position. Transactions of the British Mycological Society 34, 23-34.

Neter, E., AnZAI, H. \& Gorzynski, E. A. (1960). Identification of an antigen common to Listeria monocytogenes and other bacteria. Proceedings of the Society for Experimental Biology and Medicine I05, I 3 I - I 34 .

OpINION No. 32. (1970). Conservation of the specific epithet rhusiopathiae in the scientific name of the organism known as Erysipelothrix rhusiopathiae Migula 1900, Buchanan 1918. International Journal of Systematic Bacteriology $\mathbf{2 0}, 9$.

Pacheco, G. \& Santos, M. L. (1957). Bacterioimpediencia de materias corantes sobre listerias. Revista Brasileira de Medicina 14, 316-319.

PACKER, R. A. (1943). The use of sodium azide and crystal violet in a selective medium for streptococci and Erysipelothrix rhusiopathiae. Journal of Bacteriology 46, 343-349.

Pease, P. E. (1967a). Tolerated infection with the sub-bacterial phase of Listeria. Nature, London 2x5, 936-938. 
PeASE, P. E. ( $1967 b)$. Antigenic relationships between oral group D streptococci, some haemophilus species and Mycoplasma hominis. Journal of General Microbiology 49, 433-441.

RoBerts, R. J. ( I 968). Biochemical reactions of Corynebacterium pyogenes. Journal of Pathology and Bacteriology 95, I $27-130$.

Seeliger, H. P. R. (1961). Listeriosis, pp. 30, 2 16. Basel: S. Karger.

SEYFRIED, P. L. (I968). An approach to the classification of lactobacilli using computer-aided numerical analysis. Canadian Journal of Microbiology 14, 313-3 I8.

SharPE, M. E. (1952). Group D streptococci in the faeces of healthy infants and of infants with neonatal diarrhoea. Journal of Hygiene 50, 209-228.

Shaw, C. \& Clarke, P. H. (I955). Biochemical classification of Proteus and Providence groups. Journal of General Microbiology 13, I55-16I.

Shimwell, J. L., Carr, J. G. \& Rhodes, M. E. (1960). Differentiation of Acetomonas and Pseudomonas. Journal of General Microbiology 23, 283-286.

Skerman, V. B. D. (1967). A Guide to the Identification of the Genera of Bacteria, 2nd edn, p. 213. Baltimore: Williams \& Wilkins.

Sokal, R. R. \& Michener, C. D. (1958). A statistical method for evaluating systematic relationships. University of Kansas Scientific Bulletin 38, 1409-1438.

Welshimer, H. J. \& Meredith A. L. (1971). Listeria murrayi sp.n.: a nitrate-reducing mannitol-fermenting Listeria. International Journal of Systematic Bacteriology 21, 3-7.

Wilson, G. S. \& Miles, A. A. (1955). Principles of Bacteriology and Immunity, $4^{\text {th }}$ edn, vol. I, p. 53 I. London: Edward Arnold. 